\title{
Mortuary Rite Among the Mishing Tribe in a Rural Context of Assam
}

\author{
Arifur Zaman \\ Dibrugarh University, Dibrugarh, India
}

\begin{abstract}
Death is one of the urgent crises event in human society that occur during the lifecycle of each individual. It has an integral relation with religion, especially with rites and rituals, through which the deceased person is appeased with the intervention of supernatural. Furthermore, the death rites, popularly known as funeral rites, which incorporate the deceased into the world of the dead are more extensively elaborated and assigned the greatest importance. Mourning is integral element related with the death and during the event social life is suspended for all those affected by it and length of the period increases with the closeness of social ties with the deceased. In every society, there are certain customs related to death, as well as disposal of the corpse which reflect the parochial belief system associated with the event. In this paper, an attempt has been made to evaluate the customs associated with disposal of the death, integral parochial religious rites and rituals among the Mishings of Upper Assam, India.
\end{abstract}

Keywords: Mishing, death, oblation, Assamese Hindu, Vaishnavism

\section{Introduction}

Death implies the termination or end of life of an individual. It is an important event related particularly to the humankind of each culture and civilization of the world. However, in common parlance, death refers to the moment at which life ends. When death occurs to an individual, it requires drawing precise conceptual boundaries between life and death. One of the difficult tasks of defining death is to distinguish it from life of an individual. Life of an individual is defined on the basis of consciousness, and when consciousness ceases, a person is said to have died. Death describes a situation where something has ceased, in human society it is life. This is followed by care of the dead as well as afterlife and disposal of it upon the onset of death. Disposal of human corpse is often defined as the practice of dealing with the dead and practices regarding corpse disposal, is integrally a religious part of every culture and civilization. There are many intangible aspects of culture associated with the death and disposal of corpse, which have intricate relation with the religion of that culture. It is often followed by observance of some customs, rites and rituals, as well as ceremonies. "Ceremonies may be performed for the dying. The ritual treatment of the dead usually includes far more than the actual funeral ceremony, usually beginning at death and continuing at intervals for many years" (A Committee of the Royal Anthropological Institute of Great Britain and Ireland; 1954, p. 129).

Death is considered as one of the important rites de passage in human society. Rites de passage are

Arifur Zaman, Ph.D., Assistant Professor, Department of Anthropology, Dibrugarh University.

Correspondence concerning this article should be addressed to Dibrugarh University, Dibrugarh, Assam, India, Pin: 786004. E-mail: arifurzaman@gmail.com. 
connected with the critical, but usually expectable events of the life cycle of an individual like birth, sexual maturity, marriage, death, etc. Van Gennep (1960) defined the rites of passage which usher individuals through the crucial crisis of their lives, such as birth, puberty, marriage, parenthood, advancement to a higher class, occupational specialization, and death. Among all the crises, rite death is considered as the end phase of the life cycle of an individual and it involves elaborate funeral rites. After the death of a person, a community generally observes different taboos, rituals, and customs are followed by the family members and kins of the deceased. In this paper, an attempt has been made to evaluate the disposal of death as well as integral rites and customs, among the Mishings of Chainaki Mishing Gaon, a homogeneous village, inhabited by the Mishings only, at Tinsukia District, Assam, India.

Death and disposal are integral elements of each culture, which have indispensable relations with belief system of the society. Elaborate ethnographic studies on different communities regarding the customs, taboos, rituals, related to death and disposal were carried out by a good number of scholars like Webster (1948), Weber (1958), Van Gennep (1960), Wallace (1966), Yinger (1970), Nottingham (1971), Norback (1974), Troise(1978), Medhi (1980; 1981; 1982; 1983; 2012), Mills (1980), Bordoloi (1984), Neog (1984), Panchani (1987; 1989), Sharma Thakur and Saikia (1987), Playfair (1998), Venugopal (1998), Gurdon (2002), Endle (2007), Zaman (2010; 2012), et al., and they also focus on the correlation of religious beliefs and practices regarding death with social life.

\section{The Mishings}

The Mishings are the second largest scheduled tribe of the plain areas of the state Assam. They inhabit the riverine areas of the Dibrugarh, Jorhat, Lakhimpur and Sonitpur districts of the state. They are patrilineal and descent, inheritance, authority, succession and residence after marriage are traced through male line among them. As they basically live in riverine areas, they adjust to their environment by constructing their dwelling houses in raised platform. They believe in numerous benevolent and malevolent spirits (uie) and they offer propitiations and observe different rituals during their crises period as well as in relation to different diseases and ailments. The principal economy of the Mishings is agriculture and fishing along with domestication of animals like pig, goat, cow, buffalo, etc., along with petty trades and wage earning. Few of them are also engaged in governmental and nongovernmental jobs. Traditionally they are the followers of Doni-Poloism, the cult of Sun and the Moon god. At present, they are influenced by other religious faiths, mostly by Hinduism and Christianity. However, in the study village, they are seeming to be mostly influenced by Hinduism due to which many traits of the Hinduism have been noticed amongst their socio religious life. In spite of that they have been maintaining their traditional customs and values along with the new religious faith.

The abode of Mishings is surrounded by caste Hindu population of Assam, due to which cultural traits of Assamese caste population is noticed into their norms and patterns of life. They are mainly influenced by Assam's Vaishnavism, a parochial religious cult introduced by the Vaishnavite Saint Srimanta Sankaradeva and his principle apostle Madhavadeva. In this religion, the followers worship only the Lord Vishnu as their supreme god along with His principal incarnation Lord Rama and Lord Krishna. There is no idol worship in Assam's Vaishnavism. Satra (Vaishnavite monastery) is the supreme community worshiping place of this religion along with namghar, the village level worshipping place affiliated to the satra (Zaman; 2009). There is a namghar in the Chainaki Mishing Gaon which is visited by the people of the village for prayers and religious purposes. The chief priest of the namghar is known as the Medhi who is expert in ritualistic performances 
along with his subordinate staff, the bhakats. The Medhi along with the bhakats invariably assist the people of the village in their different ritualistic purposes, viz., rites and rituals integral to birth, initiation, marriage, death, agriculture, festival, purification, healing, along with observances of birth and death ceremonies of the Vaishnavite saints, Janmasthami (birthday of Lord Krishna), etc.

\section{The Objectives and Methods}

The present study is mainly concerned with-(i) the beliefs and practices related to the death of a person in the study population; (ii) care and disposal of the corpse; (iii) rites and rituals observed in relation to the dead; and (iv) the changing trend.

The empirical data for the present study is collected from the homogenous Mishing village named Chainaki Mishing Gaon located at Tinsukia District, Assam, India. Standard anthropological field methods like non participant observation, household survey, in depth interview and case study are employed for the collection of first hand ethnographic data. Data collected from one individual are cross checked with others for authentication of the same. Some of the secondary source materials have also been consulted to know about the community as well as about their customs in relation to the present study.

\section{Results and Discussion}

Religion plays an important role in the social structure of the Mishings of Chainaki Mishing Village. They observe elaborate rituals for different steps of agriculture, house building, birth, initiation, puberty, marriage, death, harvest, etc., which bind and control the society with the intervention of the sacred. Frazer (1870) in his networthy book Golden Bough says that by religion it is meant that a propitiation or conciliation of powers superior to man who are believed to bind and control the course of nature and of human life. Thus defined, religion consists of two elements, a theoretical and a practical, namely a belief in power higher than man, and an attempt to propitiate or please them. Karsten (1935) stated that, primitive rituals must be essentially an expression of mans instinct of self-preservation, in other words, of his desire to make existence as tolerable as possible. The relation between man and the supernatural powers, which he tries to influence by his invocations, prayers, and offerings is not originally an ethical relation. Various practices and beliefs serve a variety of psychological and social functions of religion in society. The people of the said village also observe elaborate customs, rites and rituals for the death of an individual as well as for the salvation of the disposed corpse.

As soon as death occurs the members of the family with loud wailing render the sky. The message is sent to the fellow family members, kins, neighbours, to participate in the last rite. When someone dies, the villagers suspend their works immediately for the day and throng to pay homage to the departed soul and to sympathize the bereaved family. The Mishings of the Chainaki Mishing Gaon bury their dead within their household residential unit or in their own private land. Knowing that a member will die, soon the experienced family members prepare themselves mentally and materially. Kith and kin from both within and outside the village are informed for the last sight and for necessary help and guidance. Irrespective of the place of death, i.e., away from the residence or away from the village, the dead body is always brought to the residence and buried.

In case of a normal death, the Mishing generally keep the corpse in the kitchen with its head facing west. The reason behind is that they consider the kitchen to be a very sacred place and all the rites and rituals related to their daily life are performed in their kitchen only. Then the corpse is carefully washed by the nearest 
relatives, the arms and legs straightened out, the head anointed with oil, and the hair reverently combed. The dead person's body is then clothed with new garb putting in reverted manner. A coin along with few rice grain wrapped in a banana leaf is placed inside the left underarm of the deceased. They invited a Medhi (ritual specialist) and the villagers that gathers prepares the bamboo bier (changi) with two hollow bamboo tubes of 8-9 feet long are placed parallel to each other, on which five bamboo sticks are placed horizontally and the knots are tied in the anticlockwise direction. Then five bamboo sticks are placed on the bier and tied vertically, above which the corpse is placed. The corpse is taken out from inside of the kitchen and is kept on the courtyard placing the head in the west direction. The Medhi lights an earthen lamp and incense sticks and then all the family members and the relatives present bow down in front of the corpse along with a sarai (disc on stand) consisting a pair of betel nuts and betel vine leaf and some money, pray for the departed soul's eternal peace. Thereafter, the villagers too bow down and everyone donates some money according to their capacity in the sarai so that the family could perform the burial rites of their dead relative properly. The dead body is then taken to the burial ground for the performance of the last rites.

In that mortuary procession of relatives and mourners, the corpse is carried by four persons consisting of the sons and other uterine kins to the burial ground. The procession is headed generally by the eldest son or in absence of him any nearest kin, who takes a braided wisp of straw used for carrying fire by lighting one of its ends (jumuthi). Meanwhile, the Medhi prepares the holy water, locally known as Shantipani, prepared by adding sweet basil leaves in water in a small bronze bowl reciting spells by the ritual expert and sprinkles it throughout the house. After reaching the burial ground, at first the land where the deceased will be buried has to be purchased ritually for the sake of the dead by the relatives by throwing a coin and some rice. The first digging should be started with the left hand; if someone's father dies then his son will start the digging first then only the other person helps in digging. A grave is dug in east-west direction of about $6 \mathrm{ft}$ in length, $3 \mathrm{ft}$ in width and about 4-5 ft in depth. After the digging is over the deceased's sons, nearest kins and fellow villagers present there pass round the grave in anticlockwise direction five times in order to prevent the spirits of other men from interfering to the repose of the deceased and then is laid over five horizontally placed bamboo sticks, facing the head towards the western direction as opposite to the normal sleeping position of east. After that some bamboo sticks are put in an inclined position with some dry leaves over it and then soil is placed on it, so that the corpse does not come in direct contact with the soil. All those attending the burial event put some amount of soil in the grave with the left hand. They bury a dead person with a few rice grains and a rupee or two wrapped in a banana leaf in both of the deceased underarms for the reason that during his journey towards the world of the dead he has to cross a river, for which a small tax is required. They believe that with the help of that coin and grain, he can overcome the situation. The personal belongings like clothing, foot wares, utensils, tools and implements, even the favourite food items of the deceased during its life time are also buried along with the corpse so that the departed soul could use those things in the land of the dead.

After soil is put over the grave, a white sheet of cloth is placed over it, tiding the four corners of the cloth into four small bamboo sticks, so that it cannot touch the soil and get polluted. Some people also put mosquito nets over the grave, as a symbolic sign of protecting the same from the entry of malevolent spirits. The area is thereafter encircled with bamboo fence to ward off the wild animals to enter in it. After the burial customs are over the people returns to the deceased's home. In the gate of the deceased house a fire is lit and each person enters to the house by crossing the fire. It is believed that evil spirits may accompany the persons coming from burial ground and they will be restricted by fire to enter to the residential unit because they are afraid and 
cannot cross fire. The persons taking part in burring the dead purify them by touching the holy water. In the evening, every household of the village lit a fire of husk and thatch in front of their household compound gate so that no malicious power can enter inside and harm them. The family of the deceased takes boiled food for three days. Consumption of meat, fish, egg, chilies, oil, etc., is strictly tabooed during this period. The family members also offer meal in the name of the deceased person in the southern direction outside the house up to the third day of the death of a person.

\section{The Rites and Rituals}

Death in the family of someone is considered as unholy and hence some purificatory rituals are always observed by the Mishings. Haviland (1978, p. 333, 342) said ritual is religion in action, and prayer is a common form of ritual. Religious ritual is the means through which persons relate to the sacred; it is religion in action. Not only is ritual the means by which the social bonds of a group are reinforced and tensions relieved, it is also one way that many important events are celebrated and crises, such as death, are made less socially disruptive and less difficult for the individual to bear. Among the Mishings soon after the dead body is taken out from the house towards the cremation ground, the rest of the family members as well as the relatives and co-villagers wash the floor and plinth of the house and sprinkle holy water on all corners of the household to make it pollution free. After three days, the Mishings observe another ritual known as tilani. On that day, the bhakats from three different lineages are invited to bless the deceased and his family. Rice is prepared along with pulses, leafy vegetables and also a fowl is sacrificed. The invited guests are offered the prepared meal along with rice beer (apong). The bhakats catches a fire with husk of paddy in the hearth of the kitchen and in that fire rice is cooked. Thereafter, two plantain leaves are placed at the floor of the kitchen on which the burnt husk, cooked rice and apop, i.e., a circular cake which is made of rice flour and some wild herbs, which is used to prepare apong, are all mixed together. Then the leaves are folded and kept on the hanging bamboo platform (parap) over the hearth meant for preservation of food item by heat and smoke emitted from it. This is the mixture generally used for a special kind of rice beer (poro apong) from the ash of the same by the Mishing and also used in the mortuary rite (Puide) observer after a month.

Puide is the ritual performed after a month of the death. One red coloured cock and one red coloured hen along with poro apong are essential ingredients in this Puide ritual. All the village people along with the bhakats are invited to perform the same. An earthen lamp is lit in the eastern direction of the kitchen by the bhakats. Two fowls are sacrificed inside the kitchen. No cooking activities are done until evening and after sunset the same has been started. Soon after the food is cooked the head of the family pours poro apong in the three points of the tripod stand of the hearth (kirae) and takes some cooked food which is put in the maram, that is four corners of the hearth, declaring that from that day all the connections with the deceased are given up and pray that the soul of the deceased reaches heaven. Then a feast is arranged for the villagers.

Dodgang is the final mortuary ritual of the Mishings of the study village. It is a community feast where the fellow villagers including the persons involved in funeral procession are invited where pigs and fowls are sacrificed and served it to the invited guests. There is no fixed time for observing this ritual and it is arranged in a suitable time depending on facilities and economic conditions of the deceased's family. As it is an expensive affair the villagers observe this ritual when they can afford. Generally it is held after one year. The Medhi is invited for performing the Dodgang. He is welcomed to the house of the deceased with beatings of drums. A type of cloth (cheleng chadar) made from a specific thread locally known as pakua suta is laid upon the place 
where he is to sit. In the morning, the hair of the son of the deceased is shaved. At night, a kind of ritual related to the worshiping of the ancestors known as Janani Puja is performed. In the Janani Puja, the ancestors are informed or let to know about the observance of the Dodgang ritual. Prayer that is related to their new faith Assam's Vaishnavism, i.e., nama-kirtan also takes place after that. Simultaneously with the nama-kirtan, the preparation of food is also continued. Only bhakats are allowed to take part in cooking. After the nama-kirtan, the sacred food is distributed to everyone.

The fact that Dodgang ritual is an expensive affair is evident from the custom of presenting the main bhakat who takes part in the rituals a whole lot of things which includes clothing like shirt, dhoti, i.e., a piece of cloth worn to cover the lower part of the body by an adult male, gamocha (a traditional Assamese towel), blanket, mattress, pillows (two), mat, and many objects which an individual requires. Rupees one thousand or two is also offered to him. His wife is also presented a full set of garb including the footwears.

The pig for that day is sacrificed by the bhakats inside the kitchen. Certain rites are followed while sacrificing the pig. Before killing it, few drops of water are sprinkled over the pig. Then on the left side of the animal, few grains of rice are thrown uttering the name of the deceased person, that the Dodgang rites are being performed and may his or her soul rest in eternal peace. After that, a stick of bamboo is straightly put across the pigs back crossing its heart and the pig is thus killed. Meat from the pig is taken out in long pieces. The family members then bow down for the eternal peace of the deceased one after the cooking and other preparations are done.

For the deceased soul, oblation (urom apin) is also offered on that day. Pork and poro apong are essentially required for oblation. For a dead person, two holes are duged in one corner of the garden after cleaning the area with water. Then in the holes the cooked food along with pork, poro apong and water are put upon which banana leaves are laid upside down facing the west direction in a reverted manner and serving with the left hand. This ritual is usually performed by the elder most son or daughter-in-law of the deceased. The husband of a deceased woman does not offer oblation for his wife. It is performed to satisfy the departed soul. They pray to the deceased that they have completed his/her mortuary rituals and request him/her to give up all connections with the family and rest in peace in the land of the dead. After the completion of the ritual a feast is offered to all the invited guests.

The customs that already discussed are observed by the Mishings in the Chainaki Mishing Gaon in case of a normal death. If a person dies in an accident outside the household, they observe different custom for his or her burial. The Mishings of the study area consider their kitchen as most sacred place of the residential unit so the unnatural death cases are never considered to perform inside the kitchen. Instead they kept the corpse in the courtyard of the house and thereafter they buried the dead like that of a normal death. The Mishings of the village also follow the same practice of burial of the dead, in case of suicide, death of a pregnant woman and child. They bring the corpse by observing the already mentioned customs to the place of burial. After selecting a suitable place, they dug a grave in the east-west direction. The corpse is placed inside the grave, a coin and some amount of rice grain wrapped inside the plantain is leaf which is inserted into the under arm and the head is placed towards the west. Earth is then laid over it, on the top of which the dead man's mat and bier are laid and covered with small branches, leaves, bamboo splits, the others. Death by suicide is considered as inauspicious among them and in all these cases they never observe the Dodgang, the most elaborate mortuary ritual of the Mishings. 


\section{Conclusion}

The study Mishing population has adopted Vaishnavism abandoning some of the pristine animistic customs and rituals. In their culture a conspicuous synthesis of animism and Vaishnavism can easily be observed. The Assamese Hindus cremated their dead; but these study people buried their corpses. Sacrifices of animal and eating of fowls and pigs are strictly prohibited in Assam's Vaishnavism; but in most of the rituals of the Mishings including the mortuary rites sacrifices of fowls and pigs are indispensable. Moreover they use country liquor in mortuary rites and all other rituals which is rigidly tabooed in Assam's Vaishnavism. Although the study population differs from the Assamese Hindus in some aspects of their culture, Vaishnavism has mosaic the study Mishing culture to a great extent and they practice both pristine animistic and adopted Vaishnavism parallely. The ritual experts like Medhi and bhakat are new addition to the traditional Mishing culture. In the writing of the author like Pegu (1981), Bordoloi, Sharma Thakur and Saikia (1987), Medhi (1995), Kagyug (1998), one can have the ritualistic observances of the animistic Mishings. The study Mishing population is in a transitional phase, which has adopted Vaishnavism in the recent past but has not abandoned animism totally for the sake of the new faith. Use of holy water, copper pot and sarai, purchasing of the land where the deceased has to be cremated, covering of the grave with a piece of white cloth, observance of Tilani ritual after three days of death, etc., are adoption from the Assamese Hindus. Along with these customs they also observe some of their pristine cultural traits like Puide and Dodgang, which have made their culture a unique one.

\section{References}

A Committee of the Royal Anthropological Institute of Great Britain and Ireland. (1954). Notes and queries on anthropology (6th ed.). London: Routledge and Kegan Paul Ltd.

Bordoloi, B. N. (1984). The Dimasa Kacharis of Assam. Guwahati, Director, Tribal Research Institute.

Bordoloi, B. N., Sharma Thakur, G. C., \& Saikia, M. C. (1987). Tribes of Assam: Part-I. Guwahati, Director, Tribal Research Institute.

Dalton, E. T. (1872). Descriptive ethnology of Bengal. Calcutta: Superintendent, Government Printing Press.

Endle, Rev. Sidney. (2007). The Kacharis. Guwahati: Bina Library.

Frazer, J. G. (1870). Golden bough. New York: Doubladay, Anchor Books.

Gurdon, Major P. R. T. (2002). The Khasis. Delhi: Low Price Publication.

Haviland, W. A. (1978). Cultural anthropology. New York: Holt, Rinehart and Winston.

Kagyug, B. M. (1998). Mishing Sanskritir Alekhya. Guwahati: Bani Prakash.

Karstern, R. (1935). Origin of religion. London: Kegan Poul.

Medhi, B. K. (1980). Beliefs, rituals and ceremonies connected with principal events of the life of the Pati Rabhas of Assam. Bulletin of the Department of Anthropolog, Dibrugarh University, 9, 40-53.

Medhi, B. K. (1981). Concept of malevolent spirits among the Pati Rabhas of Assam. Buletien of the Department of Anthropology, Dibrugarh University, 10, 135-143.

Medhi, B. K. (1982). Some aspects of beliefs in Pati Rabha Society. Gauhati University Journal of Science, 28, 6-12.

Medhi, B. K. (1983). Langa: The tutelary god of the Pati Rabhas of Assam. Journal of North East India Council for Social Science Research, 7(1), 31-33.

Medhi, B. K. (1995). Ethnomedicine: A study among the mishings in a rural context. The Bulletin of the Department of Anthropology, Gauhati University, 9, 61-68.

Medhi, B. K. (2012). Religious life of the Assamese Sikhs. In K. Jose SVD, G. K. Bera, B. K. Medhi, and R. P. Athparia (Eds.), Concept of God and religion (pp. 3-23). New Delhi: Abhijeet Publication.

Mills, J. P. (1980). The Rengma Naga. Gauhati: Spectrum Publications.

Neog, M. (1984). Religions of the North East. New Delhi: Munshiram Manoharlal Publishera Pvt. Ltd.

Norbeck, E. (1974). Religion in human life: Anthropological views. New York: Holt, Renehart and Winston. 
Nottingham, E. K. (1971). Religion: A sociological view. New York: Random House.

Panchani, C. S. (1987). Manipur: Religion, culture and society. Delhi: Konark Publishers.

Panchani, C. S. (1989). Arunachal Pradesh: Religion, culture and society. New Delhi: Konark Publishers Pvt. Ltd.

Pegu, N. C. (1981). The Mishings of Brahmaputra valley. Dibrugarh: Pegupam.

Playfair, A. (1998). The Garos. Guwahati: Spectrum Publications.

Troise, J. (1978). Tribal religion—Religious beliefs and practices among the Santals. New Delhi: Manohar Publications.

Van Gennep, A. (1960). The rites of passage. Chicago: The University of Chicago Press.

Venugopal, C. N. (1998). Religion and Indian society: A sociological perspective. New Delhi: Gyan Publishing House.

Wallace, A. F. C. (1966). Religion: An anthropological view. New York: Random House.

Weber, M. (1958). The Religion of India: The sociology of Hinduism and Buddhis. New York: The Free Press.

Webster, H. (1948). Magic_-A sociological study. London: Stanford University Press.

Yinger, J. M. (1970). The scientific study of religion. London: The Macmillan Company.

Zaman, A. (2009). An anthropological study on mask of Natun Chamaguri Satra of Majuli, District Jorhat, Assam, Unpublished Thesis of Gauhati University.

Zaman, A. (2010). The Balia Baba than: Aspect of sacred complex in a Tengapania Deori village of Assam. Bulletin of the Department of Anthropology, Dibrugarh University, 38, 17-32.

Zaman, A. (2012). Aspects of death and disposal among the Tengapania Deoris of Assam. In K. Jose SVD, G. K. Bera, B. K. Medhi, and R. P. Athparia (Eds.), Concept of God and religion (pp. 263-274). New Delhi: Abhijeet Publication. 